\title{
DETERMINING PLASTIC PROPERTIES OF MATERIAL THROUGH INSTRUMENTED INDENTATION APPROACH
}

\author{
I N Budiarsa*, I N G Antara, I M Astika, I W Widhiada \\ Mechanical Engineering, Udayana University, Bukit Jimbaran Bali. Indonesia \\ *Corresponding Author E mail: nyoman.budiarsa@unud.ac.id
}

\begin{abstract}
One significant advantage of indentation tests is that this test only requires a small amount of test material, this makes it very attractive for material characterization with gradient properties where standard specimens are not available such as in situ or in vivo. Regarding tests for spot welded joints, standardized testing does not apply to characterize HAZ and nuggets because of their complex structure and small size. This has opened the possibility to characterize material properties based on the Indentation method to characterize inverse parameters of constitutive material laws for nuggets, HAZ and base metals. The numerical approach based on the Finite Element (FE) model has been developed and validated. The established formulation is used for reverse (inverse) prediction of the nature of constitutive material (ie yield stress ( $\sigma y)$ ), strain hardening coefficient (n)) for the welded joint zone namely the nugget, HAZ and parent metals (base). Then able to predict the effect of the nugget size and the thickness of the sheet metal on the strength of the spot welded joint with dissimilar material.
\end{abstract}

Keywords Indentation, Finite Element modelling, yield stress, strain hardening coefficient.

Cite this Article: I N Budiarsa, I N G Antara, I M Astika and I W Widhiada, Determining Plastic Properties of Material Through Instrumented Indentation Approach. International Journal of Advanced Research in Engineering and Technology, 10(1), 2019, pp. 249-257.

$\mathrm{http} / /$ iaeme.com/Home/issue/IJARET?Volume=10\&Issue $=1$

\section{INTRODUCTION}

Indentation testing is an important materials testing method to determine material characteristics, in which a sharp or blunt indenter is pressed into the surface of a material. It can be used to test brittle (e.g. ceramics) and elasto-plastic (e.g. metals) [1], [2]. Earlier works showed that hardness can be related to the stress of the indented material $(\sigma r)$, corresponding to a representative strain ( $\varepsilon r)$, which represents the mean plastic strain after yielding. The concept coupled with finite element (FE) modelling has been used successfully in analyzing sharp indenters where the representative strain and stress is well defined with a fixed indenter angle [3], [4]. Many works have been explored in searching a way to inversely predict material properties from indentation tests [3], [4], [5]. Most of the research has been focusing on using 
full P-h curves while the links established between the hardness and constitutive materials properties are mostly based on empirical data. For example, for elasto-plastic metals, most of the property-hardness data available had been mainly using strength (yield strength and ultimate tensile strength) [6],[7] as it is difficult to quantify the contribution of the work hardening coefficient.

One of the main problems is to characterize material properties. The parameters of elasticplastic material and material fracture parameters can be easily determined when standard tests are available. However, for spot welded joints, standard testing is not applicable to characterize HAZ and nuggets due to their complex structure and small size. Therefore requires a nonstandard method to be able to predict its characteristics more accurately. In a spot welding process two or three overlapped or stacked components are welded together as a result of the heat created by the electrical resistance [8]. The welding process is a complex thermal mechanical process and the finished assembly consists of regions with significantly different microstructures and properties, including the base metal, heat affected zone (HAZ) and weld nugget [9]. The resistance spot welding is the most widely used joining process for sheet materials [10]. Many metallic materials such as mild steel can be welded by resistance spot welding [11], [12]. Thin sheet metals [13]. Spot welding involves thermal, metallurgical and mechanical processes, which result in a structure of mixed phases and properties. There are three main different regions - the base material, the nugget and the heat-affected-zone (HAZ). The block in the center is the nugget that consists of martensitic and bainitic phases [14]. In many cases, failures of spot welded joints tend to occur around this region, specifically around the heat-affected zone [15]

The most recent research conducted is to use simulations through a finite element modeling approach to predict the dimensions and strength of welded joints [16], [17]. Another active area of research is research related to instrumentation indentation of complex structures [16]. Previous studies have shown that the hardness value is closely related to the correspondence between the representative stress ( $\sigma r)$ and the representative strain ( $(\mathrm{r})$ which is the average value of the plastic strain produced in the indentation process [18], [19]. Analysis of representative strain and stress systems based on indentation Instrumentation with sharp indenter (Vickers) using a fixed indenter angle, through a numerical approach finite element model has been developed. In this case the relationship generated between the parameters of the material properties with the strength - indentation depth (ph curve) is finally used to estimate the hardness of the material parameters. Simulations with validated models have been carried out over various ranges of material properties $(\sigma \mathrm{y}: 100-900 \mathrm{MPa}$, and $\mathrm{n}: 0.0-0.3)$ the relationship between yield stress $(\sigma \mathrm{y})$, strain hardening coefficient $(\mathrm{n})$, and known values hardness (HV). This will lead to the prediction results of their plastic properties $(\sigma y$ and $n)$ at the weld spot joints because of their complex structure, which can be predicted more accurately through instrumentation indentations.

\section{MATERIALS AND EXPERIMENTAL}

Specimens for spot welded with dissimilar materials consisting of two materials (stainless steel G304 and mild steel (MS)) were used in this study. As stated in Table.1 
Determining Plastic Properties of Material Through Instrumented Indentation Approach

Table 1. Chemical composition of material spot welding specimens

\begin{tabular}{|l|lllllllll|}
\hline Concentration & $\mathbf{C}$ & $\mathbf{C r}$ & $\mathbf{N i}$ & $\mathbf{M n}$ & $\mathbf{S i}$ & $\mathbf{P}$ & $\mathbf{S}$ & & \\
\hline G304 & $<0.08 \%$ & $17.5-20 \%$ & $8-11 \%$ & $<2 \%$ & $<1 \%$ & $<0.045 \%$ & $<0.03 \%$ \\
\hline MS & $0.14 \%$ & $0.01 \%$ & $0.01 \%$ & $0.32 \%$ & $0.03 \%$ & $0.2 \%$ & $0.05 \%$ & \\
\hline
\end{tabular}

The material specifications are respectively for width and thickness of G304 (25 mm; 0.8 $\mathrm{mm})$ and MS (25 mm; $1.44 \mathrm{~mm})$. Spot welding process is applied to dissimilar welded joints. Various combinations of Hardness Tests are carried out on welded joints and parent metal. The Vickers hardness test was carried out using the Duramin-1 Struers Vickers hardness testing machine using the direct loading method with various loads from $19.61 \mathrm{~N}$ to $490.3 \mathrm{mN}$. The indenter used has the right pyramid shape with a square base and $136^{\circ}$ angles facing opposite sides [18], [20] while the shear test is applied to a welding joint of better sheet metal using a Lloyd LR $30 \mathrm{~K}$ Universal fuel engine with maximum capacity $30 \mathrm{KN}$ with accurate readings of up to $0.5 \%$ of strength. This machine is connected to a microcomputer which allows graphical output of the results and data obtained and stored. This machine is used to tensile test and shear compression. Tensile test specimens were carried out using an initial load of about $50 \mathrm{~N}$, the specimens were clamped with two gaskets to avoid bending during testing. Tensile testing is carried out at a loading rate of $5 \mathrm{~mm} / \mathrm{min}$ based on ASTM E 8-04

\section{RESULTS AND DISCUSSIONS}

\subsection{Identification of Materials Parameters}

The plastic behavior is normally described by the constitutive material equations. In many cases, the three parameter power law hardening rule (Eq.1) is used for steels:

$$
\sigma=\sigma_{0}+K \varepsilon
$$

Where the parameter $\left(\sigma_{0}\right)$ is the yield stress, $K$ is the strength coefficient and ' $\mathrm{n}$ ' is the strain hardening coefficient. These material parameters influence both the yielding strength and work hardening behavior of the spot welded joint. The ratio L/Lo is the extension ratio, denoted as $\lambda$. Using these relations, it is easy to develop relations between true (t) and engineering (e) measures of tensile stress and strain.

$$
\begin{aligned}
\sigma_{t}= & \sigma_{e}\left(1+\varepsilon_{e}\right)=\sigma_{e} \cdot \lambda \\
& \varepsilon_{t}=\ln \left(1+\varepsilon_{e}\right)=\ln \cdot \lambda
\end{aligned}
$$

Following the Hooke's law and Von Misses yield criterion with isotropic power law hardening, reverse the dependence of the true stress oon the true strain $\left(\varepsilon_{t}\right)$ Eq. (2) the dependence of the strain on stress is commonly expressed by Eq. (3).

$$
\varepsilon=\left\{\begin{array}{c}
\sigma / \mathrm{E} \quad \text { for } \sigma \leq \sigma_{\mathrm{y}} \\
\sigma_{\mathrm{y}} / \mathrm{E}\left(\frac{\sigma}{\sigma_{\mathrm{y}}}\right)^{1 / \mathrm{n}} \text { for } \sigma>\sigma_{\mathrm{y}}
\end{array}\right.
$$

As shown in the Figure 1, $\varepsilon_{\mathrm{r}}$ is a particular plastic strain point, the stress at the point (representative stress, $\sigma_{\mathrm{r}}$ ) can be directly linked to the hardness. The representative strain, $\varepsilon_{\mathrm{r}}$, represents the mean plastic strain defined by Tabor $(1948,1951)$. Such a technique allows estimating one point on the true stress-true strain curve (Figure 1), at which, the stress can also be expressed as:

$$
\sigma_{\mathrm{r}}=\sigma_{\mathrm{y}}\left(1+\frac{\mathrm{E}}{\sigma_{\mathrm{y}}} \varepsilon_{\mathrm{r}}\right)^{\mathrm{n}}
$$

where $\mathrm{E}$ is Young's modulus, $\mathrm{n}$ is the strain hardening coefficient. In the plastic region strain can be described as yield strain $\left(\boldsymbol{\sigma}_{\mathbf{y}}\right)$ and true plastic strain. 
Due to the complex structure of the welds to find out the behavior of the nature of the failure and fracture of the weld spot joints more use the Gurson Model approach. This model is widely applied in ductile fracture mechanics, where material fractures are thought to be the result of void growth in the volume of material. The Gurson model most commonly used in failure behavior analysis is the Gurson Tvergaard Needleman (GTN) model [22] the model approach assumes that the plastic properties are produced from a porous material, where the yield surface is a function of emptiness formulated as follows

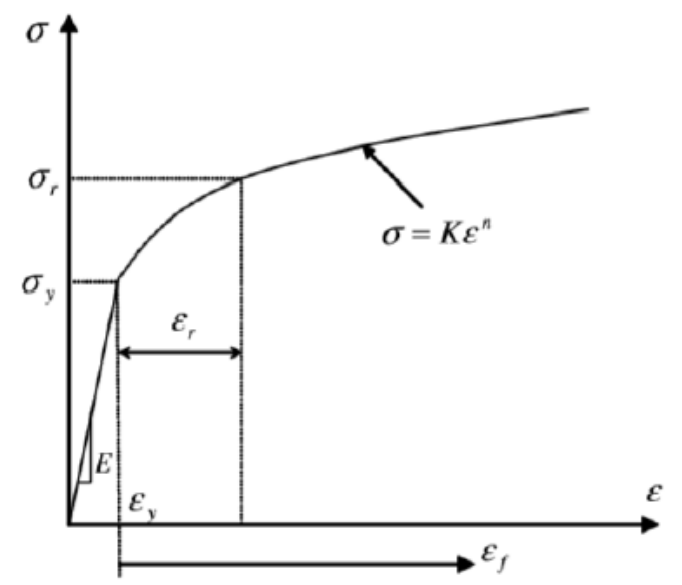

Figure 1 The power law elasto-plastic stress-strain behaviour and representative stress concept. (Cao et al., 2004) [21]

$$
\Phi=\frac{3 S_{j k} S_{j k}}{2 \sigma_{y s}^{2}}+2 q_{1} \mathrm{f} \cosh \left(\frac{3 q_{2} \sigma_{m}}{2 \sigma_{y s}}\right)-\left(1+q_{3} \mathrm{f}^{2}\right)=0
$$

where $\sigma_{\mathrm{y}}$ is the yield stress of the material, $\sigma_{\mathrm{m}}$ is the average stress, $\mathrm{f}$ is the volume fraction of voids. $\mathrm{f}=0$ means that the material is fully dense and conditions Gurson yield reduces von Mises; $f=1$ means that the material is full void and has no stresses. $S_{j k}$ is a component of the deviator $(\mathrm{j}, \mathrm{k}=1,2,3)$, is defined as $\mathrm{S}_{\mathrm{jk}}=\sigma_{\mathrm{jk}}-\sigma_{\mathrm{m}} \delta_{\mathrm{jk}}$ and $\delta_{\mathrm{jk}}$ is Kronecher delta $\delta_{\mathrm{jk}}=1$ if $\mathrm{j}=\mathrm{k}$ and $\delta_{\mathrm{jk}}$ $=0$ if $\mathrm{j} \neq \mathrm{k}$. while the parameter values $\mathrm{q}_{1}, \mathrm{q}_{2}, \mathrm{q}_{\mathrm{B}}$ are material constants, the values most found in most of the literature are as. $\mathrm{q}_{1}=1.5, \mathrm{q}_{2}=1, \mathrm{q}_{3}=2.25$. In the indentation process of a power law elastic plastic solid, the load $\mathrm{P}$ must be a function of the following independent parameters: $\mathrm{P}$ is the force, $\mathrm{h}$ is the depth, $\mathrm{E}_{\mathrm{i}}$ is Young's modulus of the indenter, and $\mathbf{v}_{\mathbf{i}}$ is its Poisson's ratio. [3]

$$
\mathrm{P}=\mathrm{P}\left(\mathrm{h}, \mathrm{E}, \mathrm{v}, \mathrm{Ei}, \mathrm{vi}, \boldsymbol{\sigma}_{\mathrm{y}}, \mathrm{n}\right)
$$

Where $\mathrm{E}=$ Young's modulus indenter, and $\mathrm{v}=$ Poisson ratio. By combining the effects of the elasticity of an elastic indenter and elasto plastic solid can be written:

$$
\begin{aligned}
& \mathrm{P}=\mathrm{P}\left(\mathrm{h}, \mathrm{E}^{*}, \boldsymbol{\sigma}_{\mathbf{y}}, \mathrm{h}\right) \text { or } \\
& \mathrm{P}=\mathrm{P}\left(\mathrm{h}, \mathrm{E}^{*}, \boldsymbol{\sigma}_{\mathrm{y}}, \boldsymbol{\sigma}_{\mathbf{r}}\right)
\end{aligned}
$$

Where

$$
\mathrm{E}^{*}=\left[\frac{1-\mathrm{v}^{2}}{\mathrm{E}}+\frac{1-\mathrm{v}_{i}^{2}}{\mathrm{E}_{i}}\right]^{-1}
$$

In this work, the main material group to be investigated is steel, so the $\mathrm{E}$ value is fixed at $200 \mathrm{GPa}$ rather than using true $\mathrm{E}^{*}$ value $\left(\sim 187 \mathrm{GPa}\right.$ with $\mathrm{E}_{\text {indenter }}=1220 \mathrm{GPa}$ and $\mathrm{E}_{\text {steel }}=200$ $\mathrm{GPa}$ ) to avoid uncertainty in the value of $\mathrm{E}^{*}$ from different sources. So Eq.(7) can be simplified as $\mathrm{P}=\mathrm{P}\left(\mathrm{h}, \mathrm{E}, \sigma_{\mathrm{y}}, \mathrm{n}\right)$ and incorporating Eq.(4), Applying the $\Pi$ theorem in dimensional analysis, Eq. (8) becomes 
Determining Plastic Properties of Material Through Instrumented Indentation Approach

$$
\mathrm{P}=\sigma \mathrm{t} \mathrm{h}^{2} \prod 1\left(\frac{\mathrm{E}}{\sigma_{\mathrm{r}}}, \mathrm{n}\right)
$$

than

$$
\mathrm{C}=\frac{\mathrm{P}}{\mathrm{h}^{2}}=\sigma_{\mathrm{y}} \Pi 1\left(\frac{\mathrm{E}^{*}}{\sigma_{\mathrm{y}}}, \mathrm{n}\right)
$$

Where $\prod 1$ is a dimensionless function. similarly, applying the theorem to equation (9), loading curvature $\mathrm{C}$ may alternatively be expressed as [3]

$$
\mathrm{C}=\frac{\mathrm{P}}{\mathrm{h}^{2}}=\sigma_{\mathrm{y}} \prod 1\left(\frac{\mathrm{E}^{*}}{\sigma_{\mathrm{y}}}, \frac{\sigma_{\mathrm{r}}}{\sigma_{\mathrm{y}}}\right)
$$

in equation (8), normalization is required with respect to the yielding stress $\left(\boldsymbol{\sigma}_{\mathbf{y}}\right)$ or the representatif plastic stress $\left(\boldsymbol{\sigma}_{\mathbf{r}}\right)$. Through simulation formulated the relationship between $\mathbf{C}_{\mathbf{v}} \mathrm{Vs}$ normalized relationship between material properties and normalized properties of materials of Vs $\mathbf{C}_{\mathbf{s}}$ (strain hardening exponents (n) and yield stress $\left(\boldsymbol{\sigma}_{\mathrm{y}}\right)$ ), P-h curves for Vickers and Spherical indentations has the following relationship. By establishing the relationship between $\mathrm{Cv}$ and $\sigma \mathrm{r}$, that make the P-h curves can be determined. The representative stress ( $\sigma \mathrm{r})$ is directly linked with the representative strain ( $\varepsilon r)$ chosen.
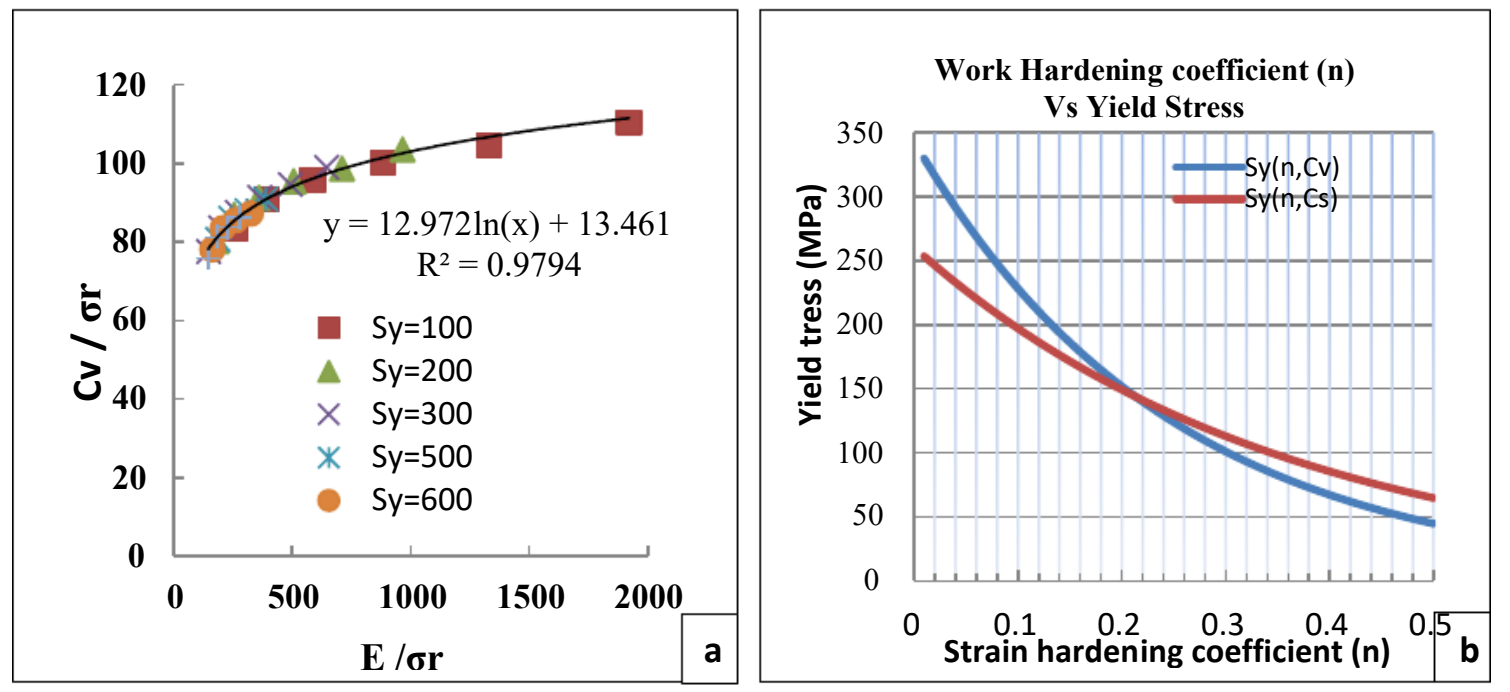

Figure 2 a) Effects of Yield strength $\left(\boldsymbol{\sigma}_{\mathbf{y}}\right)$ on the value loading curvature $\left(\mathbf{C}_{\mathbf{v}}\right)$ and work hardening coefficient (n) on Vickers Indentation. b) Typical materials parameter prediction process based on the intersection between properties line for the Vickers and Spherical indentation $\left(\boldsymbol{\sigma}_{\mathbf{y}}=150 \mathrm{Mpa}, \mathrm{n}=0.2\right)$

One way to find the optimum representative strain is by systematically varying the strain level until the best fitting is found between the measurement and materials parameters. In this case, the $\mathbf{C}_{\mathbf{v}} / \boldsymbol{\sigma}_{\mathbf{r}}$ and the E/ $\boldsymbol{\sigma}_{\mathbf{r}}$. Figure $2 \mathrm{a}$ ) Shows the change of coefficients of correlation vs. the representative strain used. The best correlation coefficient is found at a representative strain of 0.029 , which is slightly different from 0.033 reported [3]. Figure 2a) shows the fitting between the $\mathbf{C}_{\mathbf{v}} / \boldsymbol{\sigma}_{\mathbf{r}}$ vs. E/ $\boldsymbol{\sigma}_{\mathbf{r}}$ with the yielding stress changed from 100 to $700 \mathrm{MPa}$. The fitting was consistent with equation determined is:0.033 reported [3]. Figure 1a) shows the fitting between the $\mathbf{C}_{\mathbf{v}} / \boldsymbol{\sigma r}$ vs. E/ $\boldsymbol{\sigma}_{\mathbf{r}}$ with the yielding stress changed from 100 to $700 \mathrm{MPa}$. The fitting was consistent with equation determined is:

$$
\mathbf{C}_{\mathbf{v}} / \boldsymbol{\sigma}_{\mathbf{r}}=12.972 \ln \left(\mathrm{E} / \boldsymbol{\sigma}_{\mathbf{r}}\right)+13.461
$$

Where $\Pi 1$ is a dimensionless function, the dimensionless given in Eq.12 and the normalization was taken with respect to $E^{*}$ instead of $\sigma_{\mathbf{y}}$ or $\boldsymbol{\sigma}_{\mathbf{r}}$. Figure $2 b$ ). Show the relationship between normalized $\mathbf{C}_{\mathbf{s}}$ Vs properties material (strain hardening coefficient (n) and Yielding stress). It is clearly shown that all the data. Curve fitting has been performed by iterating the 
relationship between loading curvature indentation and properties material $(\sigma y, n)$ as following equations

$$
\mathbf{C}_{\mathbf{v}}=384.08 . e^{3.0617 n}-8.22 .56\left(\boldsymbol{\sigma}_{\mathbf{y}}\right)^{0.7282}
$$

Where $\mathrm{P}$ is load and (h) indentation depth at each load curve. $\mathrm{C}_{\mathrm{v}}$ is the Vickers indentation curvature coefficient and the ball indenter designated as $\mathrm{C}_{\mathrm{s}}$ and the Curvature is a function of the relationship between the yield stress $\left(\sigma_{\mathrm{y}}\right)$ and strain hardening coefficient $(\mathrm{n})$. This will provide a potential relationship allowing the prediction of material parameters of the test continuous indentation

\subsection{Prediction Plastic Properties Spot Welds}

The method for determining the properties of plastic materials through indentation instrumentation was developed with an inverse prediction using FE modeling with input hardness values of materials are known to identify constitutive material properties. In the first phase, finite element models that are developed systematically with simulation space boundaries cover a variety of potential material properties. In the next stage, the P-h curve established is used in the spatial boundary simulation.

A comparative approach has been developed to predict material sets based on actually indented curvature. Through force input data $(F)$ vs depth (h) related to indentation hardness value. Simulations with validated models that have been carried out on various material properties ( $\sigma \mathrm{y}: 100-900 \mathrm{MPa}$, and n: 0.0-0.5) then the relationship between the yield stress $(\sigma y)$, strain hardening coefficient (n), hardness value (HV ) can be known (Figure 3)

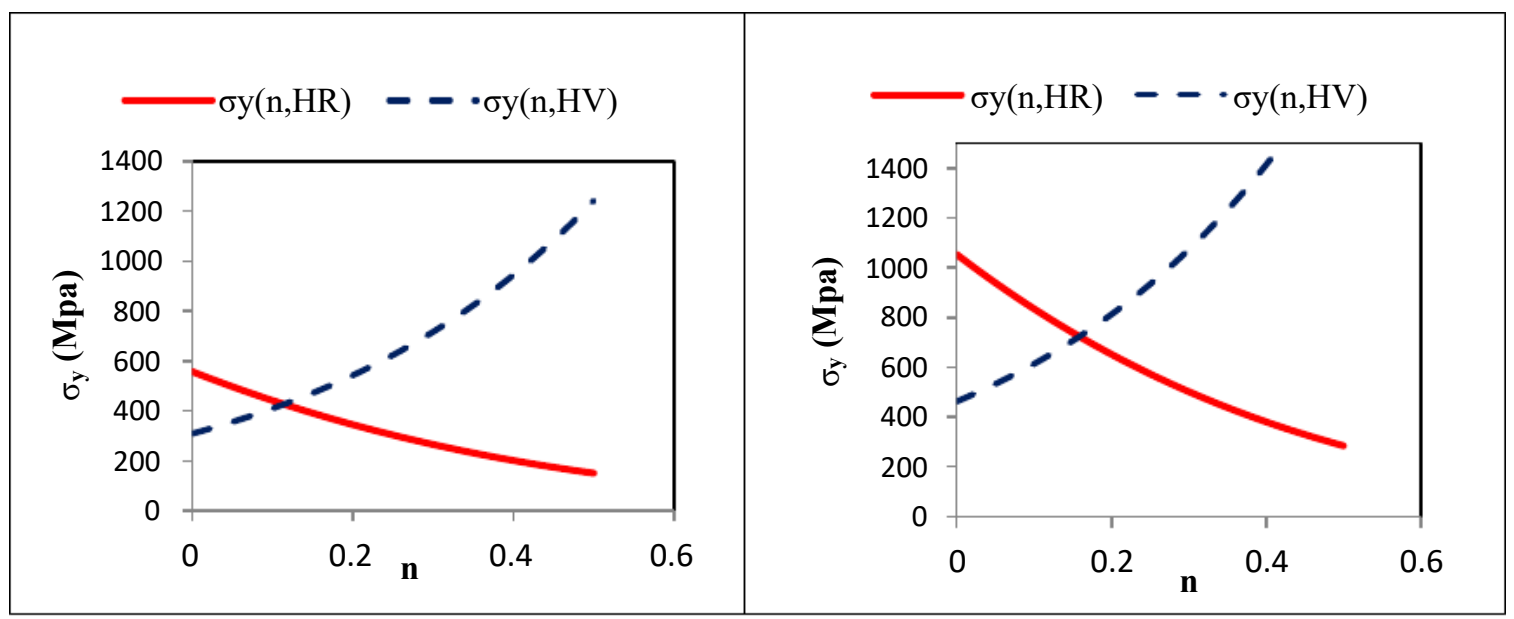

Figure 3 Typical intersection curve $\boldsymbol{\sigma}_{\mathbf{y}}(\mathrm{n}, \mathrm{HRB})$ and $\boldsymbol{\sigma}_{\mathbf{y}}(\mathrm{n}, \mathrm{HV})$ in the FE Modeling approach for the prediction of parameters constitutive material $\left(\boldsymbol{\sigma}_{\mathbf{y}}, \mathrm{n}\right)$ for the parent metal (base) 
Determining Plastic Properties of Material Through Instrumented Indentation Approach

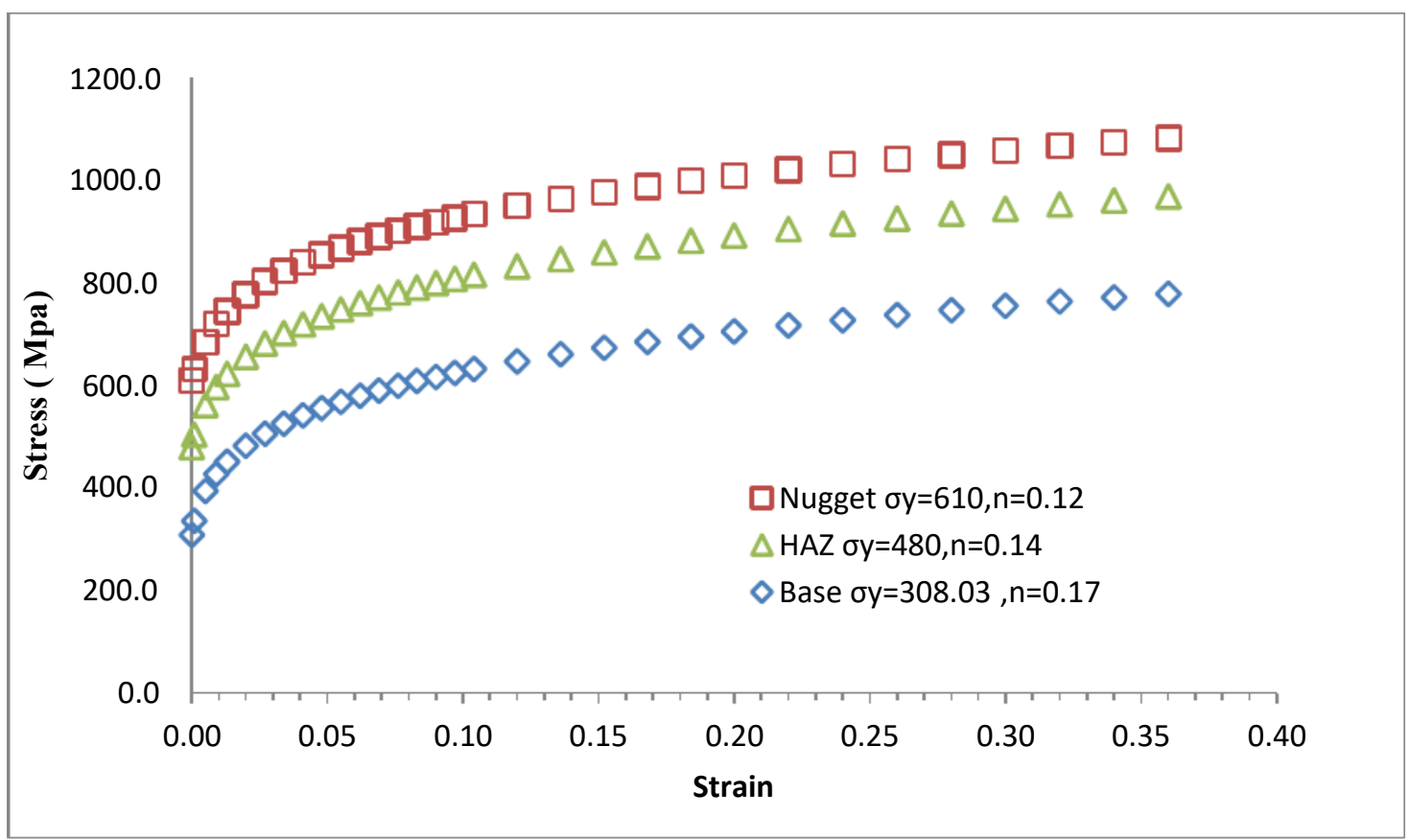

Figure 4. Typical prediction of the plasticity for Nugget, HAZ and the parent metal (base metal) as an application of FE Modeling constitutive parameters in the prediction of material $\left(\sigma_{y}, n\right)$

As shown in Figure 3 shows the relationship between modeling results with experimental data. This means that the material laws predicted $\left(\boldsymbol{\sigma}_{\mathbf{y}}, \mathrm{n}\right)$ by the Finite element-based instrumentation of indentation elements for different material weld zones are accurate. The slight differences between numerical and experimental results on the fracture behavior suggest that detailed fracture for each material zone has to be obtained rather than using parameters from the base material, which requires further investigation

\section{CONCLUSION}

In this work, FE model of Vickers indentation has been developed. The model was validated against published testing data. An approach to predict the P-h curves from constitutive material properties has been developed and evaluated based the relationship between the curvature and material properties and representative stress. The method for determining the properties of plastic materials through an inverse prediction approach uses finite elements modelling with known input hardness values to identify constitutive material properties $\left(\boldsymbol{\sigma}_{\mathbf{y}}, \mathrm{n}\right)$. has been developed and validated. The results show a good agreement with the experimental data. This means that the material law $\left(\sigma_{\mathbf{y}}, \mathrm{n}\right)$ predicted by the Finite element-based instrumentation of the indentation for different material weld zones is accurate.

An evaluation of the prediction results based on experimental data shows an accurate similarity with the numerical approach of continuous curve indentation. The developed approach has been successfully used to characterize the plasticity of different zones at spot welding. (nugget; $\sigma \mathrm{y}=610 \mathrm{MPa}, \mathrm{n}=0.12$, HAZ: $\sigma \mathrm{y}=480 \mathrm{MPa}, \mathrm{n}=0.14$, Base: $\sigma \mathrm{y}=308.03$ $\mathrm{MPa}, \mathrm{n}=0.17)$. This plastic material parameters used in finite element modeling for tensile shear deformation spot welding and welded joints showed good correlation with experimental results. Validated FE models are then used to predict the effect of nugget size and thickness of the sheet metal on the strength of the weld joint points with different materials (dissimilar material) 


\section{REFERENCES}

[1] Giannakopoulos A. E. and Larsson P. L., 1997, Analysis of pyramid indentation of pressuresensitive hard metals and ceramics, Mechanics of materials, Vol. 25, pp. 1-35.

[2] Pharr G. M., Herbert E. G., Gao Y., 2010, The Indentation Size Effect: A Critical Examination of Experimental Observations and Mechanistic Interpretations, Annu. Rev. Mater. Res. 40: pp. 271-292

[3] Dao M., Chollacoop N., Van Vliet K. J., Venkatesh T. A. and Suresh S., 2001, Computational modelling of the forward and reverse problems in instrumented sharp indentation, Acta Materialia, Vol. 49, pp. 3899-3918.

[4] Kang S., Kim J., Park C., Kim H., and Kwon D., 2010, Conventional Vickers and true instrumented indentation hardness determined by instrumented indentation tests, J. Mater. Res., Vol. 25, No. 2, Feb 2010.

[5] Chen X., Ogasawara N., Zhao M. and Chiba N., 2007, On the uniqueness of measuring elastoplastic properties from indentation: The indistinguishable mystical materials, Journal of the Mechanics and Physics of Solids 55, pp. 1618-1660

[6] Busby J. T., Hash M. C., Was G. S., 2005, The relationship between hardness and yield stress in irradiated austenitic and ferritic steels, Journal of Nuclear Materials 336, pp. 267278

[7] Gaško M., Rosenberg G., 2011, Correlation between hardness and tensile properties in ultrahigh strength dual phase steels - short communication, Materials Engineering-Materiálové inžinierstvo 18 , pp. 155-15

[8] Aslanlar S., 2006. The effect of nucleus size on mechanical properties in electrical resistance spot welding of sheets used in automotive industry, Materials and Design, $27.125-131$.

[9] Fan X., 2007. Simulation of distortion induced in assemblies by spot welding, Engineering manufacture, vol 221, 8, pp 1317-1326

[10] Chou Y., Rhee S., 2003. Relationships between quality and attributes of spot welds. Welding Journal, 195S-201S

[11] Vural M, Akkus A., 2004. On the resistance spot weldability of galvanized interstitial free steel sheets with austenitic stainless steel sheets. Material Processing Technology 153-6.

[12] Kahraman N., 2007. The influence of welding parameters on the joint strength of resistance spot-welded titanium sheets, Material and design, vol.28.iss 2, pg 420-427.

[13] Chang B.H., Zhou Y., 2003. Numerical study on the effect of electrode force in small-scale resistance spot welding, Materials processing technology, vol 139, 1-3, pg: 635-641

[14] Mukhopadhyay et al., 2009. Strength assessment of spot-welded sheets of interstitial free steels, Materials processing technology, vol 209, iss 4:1995-2007

[15] Ni K., and Sankaran M., 2004. Strain-based probabilistic fatigue life prediction of spotwelded joints, International Journal of fatigue, vol 26, 7, 763-772.

[16] Rahman M.M., et al., 2008. An Investigation into the effects of spot diameter and sheets thickness on fatigue life of spot-welded structure based on FEA, Research Journal of Applied Science, 3(1):10-15.

[17] Hou Z., et al., (2007) Finite element analysis for the mechanical features of RSW process, Journal of materials and Processing Technology, 185, 1-3, (2007)160-165

[18] N. Budiarsa, A. Norbury, X. X. Su, G. Bradley, X. J. Ren, (2013) "Analysis of Indentation Size Effect of Vickers Hardness Tests of Steels", Advanced Materials Research, Vols. 652654, pp. 1307-1310, 
Determining Plastic Properties of Material Through Instrumented Indentation Approach

[19] I.N. Budiarsa, et, al., (2015) Characterization of Material Parameters by Reverse Finite Element Modelling Based on Dual Indenters Vickers and Spherical Indentation. Procedia Manufacturing Volume 2, 2015, Pages 124-129

[20] Bucaille.J.L., et al., (2003) Determination of plastic properties of metals by instrumented indentation using instrumented sharp indentation. Acta Materialia, Vol.49,(2003) pp. 38993918

[21] Cao Y. P., Lu J.,2004, A new method to extract the plastic properties of metal materials from an instrumented spherical indentation loading curve, Acta Materialia, 52, pp. 40234032

[22] G. Cricrì, et al., (2013) A consistent use of the Gurson-Tvergaard-Needleman damage model for the R-curve calculation 24 (2013) 161-174; DOI: 10.3221/IGF-ESIS.24.17

[23] Syahrul Sariman and Abd. Rahim Nurdin, (2018), Flexural Behavior of T Shaped Reinforced Concrete Hollow Beam with Plastic Bottle Waste, International Journal of Civil Engineering and Technology, 9(4), 2018, pp. 534-543

[24] Abioye, O. P, Abioye, A. A, Afolalu, S. A, Akinlabi, S. A and Ongbali, S. O, (2018), A Review of Biodegradable Plastics in Nigeria, International Journal of Mechanical Engineering and Technology, 9(10), 2018, pp. 1172-1185

[25] Sathishkumar. S, A.V. Suresh, S.C. Sharma and Radha. H.R, (2014), Drill Ability Studies of Jute Fibre Reinforced Plastic Sandwich Structure Using Doe and Anova in Various Surrounding Condition, International Journal of Industrial Engineering Research and Development (IJIERD), Volume 5, Issue 1, January - February (2014), pp. 01-09. 